\title{
Predicting the Medals of the Countries Participating in the Tokyo 2020 Olympic Games Using the Test of Networks of Multilayer Perceptron (MLP)
}

\author{
${ }^{1}$ Pouya Fazlollahi, ${ }^{1}$ Akbar Afarineshkhaki', ${ }^{1}$ Reza Nikbakhsh \\ ${ }^{1}$ Department of Sports Science, Islamic Azad University, South Tehran Branch, Tehran, Iran.
}

Submitted 24 September 2019; Accepted in final form 13 January 2020.

\begin{abstract}
Background. International successes, especially in the Olympic Games, have become significantly important to many countries. Hence, the prediction can be better planning to gain this goal. Objectives. This study was conducted to predict the success of the participating countries in the Tokyo Olympic Games and this it was done using smart methods. Methods. This study was conducted in two stages of qualitative (determination of indicators) and quantitative (collecting data on selected countries). In the first stage of the research, through a study of research background and collecting of library data, a preliminary list of predictive indicators was identified. In the next step, semi-structured and in-depth qualitative interviews as non-random purposive were conducted with four elites aware of the subject of the research. The discussions continued until theoretical saturation. Results. According to the results of the research, the United States, China, and England will be ranked first to third in these games. The Islamic Republic of Iran will also be ranked 21 among the participating teams. Also, the coefficients of the predictive indicators of the rank of the countries participating in the Tokyo 2020 Olympic Games were calculated. Olympic Hosting. GDP per capita and the unemployment rate had the highest share in predicting countries, with $24.15 \%, 10.04 \%$ and $9.74 \%$, respectively. Conclusion. Using the theoretical model $(\mathrm{PEST}+\mathrm{S})$ and the neural network model, the countries' sports policymakers were enabled to use the identified indicators and components in their future planning to successfully participate in the Olympics Games.
\end{abstract}

KEY WORDS: Prediction Indicators, Olympic Games, Multilayer Perceptron Networks, Tokyo 2020

\section{INTRODUCTION}

The process of estimating unknown situations is called prediction. A prediction provides a prophecy of future events and can transform past experiences into predicting future events (1). Delurgio (1998) defined projection as a probable estimation or description of future conditions and values (2). In the sophisticated and advanced world of sports, making the right, scientific, and timely decisions has a significant and determinant role in success or failure. Among these, the number of criteria, the complexity of the data, and the dynamics of the environment are among the factors that pose a severe challenge to decisionmaking in sports. Nowadays, scientific methods have been chosen to predict the results of sports events; using these methods, by recognizing the factors influencing the results already gained, one can predict the results of the facts and the ranking of sports teams (3). Numerous articles have also stated that sports predictions based on data and information are quite different from those performed at random, such as lotteries (4).

*. Corresponding Author:

Akbar Afarineshkhaki, Assistant Professor

E-mail: akbarafarinesh@gmail.com 
As it's obvious, the success of an athlete, team or delegation to a large extent depends on the functional capacity of the national system and its effectiveness in using all appropriate and relevant resources (5). In the world of sports, and after professionalism took its place among all countries, staggering costs are required to achieve a top rank. Athletes and sports experts are making great efforts to gain international seats, and therefore the position of the prediction system among sport disciplines are attended to more than ever for future affairs planning. In recent years in the sports sciences, the use of mathematics and branches of modern engineering has come to the aid of managers, coaches, and experts to better plan for the future by examining countries' performance. Using these novel scientific methods, by identifying the influencing factors, we can predict the outcome of events and the rankings of countries. The importance and place of prediction are not hidden from the perspective of management science and knowledge, and in the process of scientific management, correct decision-making can be the source of many future successes that are based on predictions made on the future. Sports, like any economic, political, social, cultural and technological phenomenon, is no exception and the right decision-making must be made for the development of games. Through scientific principles, sports predictions provide appropriate guidelines and orientations to sports managers and planners. International successes, especially the progress in the Olympic Games, have become essential to many countries. Although the International Olympic Committee (IOC) acknowledges that the medal table cannot indicate a country's merit over another, politicians and planners, and even the media and press, consider the medals won in the tournament as an indicator of international success (6). This has increased the willingness and direct intervention of governments to develop these sports through significant financial investment (7).

Now the question is raised why some countries are more successful in international sports competitions and events than others. This is related to the work of politicians and planners, who tend to improve their success and position on the table. But while countries that spend a lot of money to compete with other countries are increasing, there is little evidence for the determination of the factors affecting sport success at the international level (8)If active factors are properly identified, managers and planners can target the achievement of sports success of a country with spending less time and energy so that the best performance from the delegation can be imagined at optimum cost.

Sports predictions are usually made by type in three ways:

- Methods that predict the results of a competition between two teams (9).

- Methods that predict the scores of two competitors (10).

- Methods that predict winner and conqueror of multiple races, such as tournaments, leagues and horse races (11).

About the prediction, it has always been a question of whether the predictions made by statistical methods are more accurate and reliable than those made by experts based on subjective judgments. Experts with subjective opinions, due to the use of qualitative criteria may perform better predictions than statistical models in less routine and more uncertain situations (5). Many studies are conducted for the comparison of these two methods in different fields such as medicine, college success, business decision-making, weather forecasting, macroeconomics predictions, inflation rate, political election results, etc., in most of which, statistical prediction models offered better prediction (12, 13). Some researchers are also done on sports (14, 15). In some of the researches such as Boiler \& Stackler (1), Derevenco, Albu, Duma (16), and Sieger et al. (17) have used other statistical methods such as regression or simple mathematical models. Most of the researches done on the prediction either lacked a proper way to predict the phenomenon or used simple techniques and data limited to a specific period. De Buscher et al. (18), and Ning et al. (19), have only used economic components; Iyer \& Ramesh (20), and Grant \& Johnston (21) have only used sports component, and Sotriadou \& Shilbury (22) have used political and economic parts to predict sports events.

Based on the review of the background of the present study, the researchers each have considered one or two variables affecting countries' success. One of the most essential variables in the success of nations is the sports variable. In the past researches, many components have been identified in the success of sports teams. However, the most essential practical sports components are not clearly identified. 
Various studies show that factors such as the history of the institutionalization of the National Olympic Committee in member countries, the number of Olympic disciplines in schools, the development of public sports in the states, being host and the number of athletes participating in the Olympics are among the active factors on the countries' success in terms of sports. Condon et al. (23) dealt with the prediction of countries' success in the Olympic Games in 1996 through neural networks. In this study, data from 195 countries were collected on three predictor variables and in their investigation, they concluded that the neural network model is a better tool than the regression model to predict countries' success in the Olympic Games. The economic variable is another predictor variable in previous studies. It should be acknowledged that most of the researches that have been done in sports prediction, have considered economic variables as the most critical factor among different variables $(15,22)$.

Another variable that seems to effect countries' success is the politic variable. It should be noted that the political conditions of a country, political climate and international relations between states are politic variables that can affect the economic, social, cultural, and sports conditions. Factors such as military expenditure, freedom of expression, seats by women in national parliaments, results of political elections, the number of newspaper circulations in a country, and the number of active political parties in the country are among famous and well-known political variables (24). Social and cultural variables are also among other components that are mentioned in some researches. All social phenomena, especially sports, are a reflection of the cultural system of society. Social aspects such as games are not possible without a clear understanding of culture. These characteristics are embedded in the literature, but are not mostly measurable. As a result, comparing countries is a complex process (Shafi'i, 2011). The technology variable is another predictor variable in previous studies. Today, new technologies play an important role in sports so that the slightest change in athletes' equipment can completely change the results of a competition. The growth of up-to-date technologies in games has provided athletes with innovative products and services and paved the way for success in sports competitions.
On the other hand, the growth and spread of technology in the world in recent years have also significantly contributed to the Olympic movement. Sajjadi (1999), about the 26 Olympic Games during the 20th century, observed that the Olympic Games became more popular around the world with the advancement of technology and the manufacturing of modern equipment, among which visual media, especially television, played a significant role in the introducing and popularizing of this movement. Researches show that high-technology exports, new-technology articles as the number of Internet users, making use of science labs, the number of sports patents for athletes' use of up-to-date equipment, and making use of information technology by sports federations and the National Olympic Committee can be useful in the success of sports teams (25).

Klaassen \& Magnus, in 2003, also presented a model for predicting tennis results. To design and build this model, data from Wimbledon games 1992-95 were analyzed. The given model was able to show the results of the tournament not only before the competition but due to high flexibility, and the model was also able to predict by analyzing information and data acquired during the game (9). Damask (2006), in another study titled as comparing the Olympic Games with the medal criterion, evaluated the countries' results in the Olympic Games and found that a large share of the total Olympic Games medals belonged to the United States and Russia (26). Churolv \& Flitman (2006) used the data envelopment analysis technique to rank countries participating in the Olympics Games. They used the indices of gross domestic product, population, life expectancy, and child mortality as model inputs items, and used indices of gold, silver, and bronze medal as model outputs (27). Hai (2007) was among other researchers who used the data envelopment analysis model to evaluate countries participating in the Olympic Games. Iyer \& Sharda (2009) used neural networks to predict the future performance of players (of cricket) based on their past performance since 1985 to 2006-7 (20). Kuper \& Sterken (2012) conducted a research title as participants and their performance in the 2012 Olympics. Model inputs indices included per capita income, population, the geographic distance of the countries to the host country, success in terms of the medal at the World Championships and hosting the games. Predicting the results showed that China would 
gain be ranked first with 44 gold medals and the United States would be ranked second with 33 gold medals. England, in the host country, would also be ranked fourth with 23 gold medals (28).

Overall, most of the researches conducted on prediction either lacked an appropriate method of predicting the phenomenon or have used simple techniques and data limited to a specific period. Therefore, in this study, it's tried to address these two major deficiencies using 1) novel scientific method and 2) comparative information over 40 years. According to the researches done, the present study seeks to identify and investigate all the factors affecting the success of countries in sports events and use them in the process of predicting to fill the gap existing in previous researches. It also uses Artificial Neural Networks, which are currently one of the most important data mining methods, to process data and predict countries' success in the Olympics.

So the researcher is using a data mining tool of Artificial Neural Networks to answer the question of what is the estimated ranking of the countries participating in the Tokyo 2020 Olympic Games. In the present study, it's tried that all the practical components be investigated and using new scientific methods and comparative information over 40 years, fill the gap of previous researches.

\section{MATERIALS AND METHODS}

Research Method. The study was conducted in two stages (identifying the variables and collecting data on selected countries) and included qualitative and quantitative mixed methods. In this study, a qualitative research method was used to respond to the main research question.

Research Implementation Method. In the first stage of the research, a preliminary list of predictive indicators was identified through a study of research background and collecting of library data. The first list was considered as the interview questions and the primary data collection tool. Subsequently, semi-structured and in-depth qualitative interviews were conducted with elites aware of the research subject. It is important to note that to record the information of the meetings, in addition to taking notes, a unique audio recorder was used. Due to ethical considerations, the researcher asked for permission from the interviewee to record the interview before the onset of each interview. The duration of the meetings varied, and the location of the discussion was agreed upon by the interviewee and the researcher. The five necessary but not necessarily sequential steps used to process the findings were: selecting the participants, collecting the data, arranging the results, analyzing the outcomes, and providing the executive strategies.

Then, using a theoretical sampling method, qualitative interviews were conducted with 28 persons in the population. Theoretical sampling is a type of purposive non-probability sampling design used in qualitative researches (29). In the case of necessity, some interviewees were interviewed more than once. Interviews continued until theoretical saturation. Theoretical saturation means that the data no longer creates new and different categories or add to existing class features. Additional data does not help complement and specify another group in this case and the samples after that look similar (29).

After the conduction of the interview, the results showed that 193 indicators could predict countries' success in the Olympic Games. The data analysis was done using a logical induction method. In a way that after the interviews were conducted and edited, the different opinions were coded and categorized in similar conceptual groups and then qualitatively analyzed. The coding in this study was done openly, axially, and selectively. In open coding, the researcher sought to identify the hidden concepts by reviewing the data set collected. At this stage, the central phenomenon is identified and the interpretation of the causal conditions and the resulting strategies is presented. Finally, according to the proposed model of De Buscher et al. (18), for selective coding, the theoretical model $(\mathrm{PEST}+\mathrm{S})$ was used at three macro, meso and micro levels. But it is worth noting that these three levels are always interacting and separating them was done for the sake of research accuracy. After identifying indicators, information of the selected variables for the selected countries participating in the Olympics since 1976 Montreal, Canada, to 2012, London was collected.

The Statistical Population of the Research. The statistical population included all countries participating in the different Summer Olympics $(\mathrm{N}=204)$. Among these, 73 states have not yet received even a single medal in all the Summer Olympics. For this reason, these countries are not considered in the research. Due to the limitations in collecting some information from states and also to optimally predict the software system, 
countries were selected form each continent by non-random available method (countries with available data) ( $n=42$ countries in total). Also, given the timeframe of the research (since the 1976 Montreal to the 2020 Tokyo Olympics Games), countries with at least 40 years' history of the institutionalization of the National Olympic Committee in their country were selected as the statistical sample. Table 1 shows the countries under study from different continents.

Table 1. Countries under Study from Different Continents

\begin{tabular}{|c|c|}
\hline ontinent & Countries Under Study \\
\hline Asia & $\begin{array}{l}\text { India, Iran, Japan, South Korea, Malaysia, the } \\
\text { Philippines, Saudi Arabia, Singapore, Thailand, } \\
\text { China }\end{array}$ \\
\hline Europe & $\begin{array}{l}\text { Austria, Belgium, Bulgaria, Denmark, Finland, } \\
\text { France, Germany, Greece, Hungary, Netherlands, } \\
\text { Norway, Poland, Portugal, Spain, Sweden, } \\
\text { Switzerland, Turkey, the UK }\end{array}$ \\
\hline Africa & Egypt, Morocco, Nigeria, Tunisia \\
\hline America & $\begin{array}{l}\text { Argentina, Brazil, Canada, Chile, Colombia, } \\
\text { Ecuador, Mexico, United States of America, } \\
\text { Jamaica }\end{array}$ \\
\hline Oceania & Australia \\
\hline
\end{tabular}

Research Participants. The interviewees included the following individuals:

1. Members of the Faculty of Economics (6 persons);

2. Members of the Faculty of Political Science and International Relations, (6 persons);

3. Members of the Faculty of Social Sciences, (5 persons);

4. Members of Faculty of Communication, (4 persons);

5. Members of Faculty of Physical Education and Sport Sciences (especially area of interest of Sport Management), (4 persons);

6. Senior Managers of the National Olympic Committee of the Islamic Republic of Iran (3 persons).

It should be noted that the researcher tried his best to interview experts in economics, political science and international relations, social sciences, and communications sciences who are familiar with sports.

Measuring Tools. The data collection tools are generally divided into four sections:

- In the first part of the data collection process, the variables that influence countries' performance in the Olympics were identified using library methods, including reviewing documents, documentary reports, credible scientific articles, and reliable websites.

- In the second part, the extracted questions were used based on the information collected from the interviews. Semi-structured interviews were then conducted with experts in the political, economic, social and cultural, technology, and sports areas. After interviewing these persons, the identified variables extracted from the interview process were identified, coded and categorized.

- In the third part, using credible websites, data from theoretical model components (PEST+S) were collected.

- In the fourth part, the data collected were analyzed using MATLAB software (artificial neural networks). The purpose of collecting the above information is to obtain and present a model that predicts the success of countries in the Olympic Games.

Statistical Method. In this study, MATLAB software, a set of software of machine learning, was used. One of the ways available in this software is Artificial Neural Networks (ANN). In the prediction process by neural networks using a time series, usually, a set of data is provided as input to the neural network so that the network performs extrapolation for the future by estimating the predicted system behavior. Most neural network approaches for the prediction problem use a multilayer feed-forward network through the error backpropagation algorithm or its improved and modified algorithms. In this study, Multilayer Perceptron (MLP) networks with network training of sigmoid function error of backpropagation as well as Radial Basis Function (RBF) systems were used.

It should be noted that among the identified indicators, variables that were quantitatively and objectively available over the years were entered as software inputs. Countries were ranked based on the number of gold medals won by each state in the present study. After the necessary data were collected, then, to test the conceptual model, Iran and the two countries of Argentina and the USA were randomly selected to compare the 22 predicted indicators with the actual values in 2012 to reduce the possibility of error and on the other hand, in the case of inaccurate identification of the predictor indicators, we can revise them again. Predictor variables of the semi-structured interview including urban population, education cost, age structure, real GDP, GDP per capita, trade balance, unemployment rate, total population, inflation, current account balance, life expectancy, health expenses, new technologies exports, New Technologies articles, internet 
users, military costs, countries' area, seats by women in national parliament, hosting of Olympics, total hosting of Olympics, number of athletes in the Olympic Games, and the history of institutionalization of The National Olympic Committee is in the countries.

Conceptual Research Model. According to the above definitions, the conceptual model is defined as follows:

$\mathrm{F}=\mathrm{f}\{(\mathrm{P} 1, \mathrm{P} 2, \mathrm{P} 3, \ldots, \mathrm{Pn}),(\mathrm{E} 1, \mathrm{E} 2, \mathrm{E} 3, \ldots$, En), (S1, S2, S3, .., Sn), (T1, T2, T3, .., Tn), $(\mathrm{S} 1, \mathrm{~S} 2, \mathrm{~S} 3, \ldots, \mathrm{Sn})\}$

Finally, according to the results obtained from the Artificial Neural Network, the 22 indicators were estimated in 2020, and the ranking of the selected countries in the Tokyo Olympics was estimated. In the prediction process by ANN using a time series, usually, a set of data is provided as input to the neural network so that the network performs extrapolation for the future by estimating the predicted system behavior. Most neural network approaches for the prediction problem, use a multilayer feedforward network through error backpropagation algorithm or its improved and modified algorithms. Multilayer Perceptron Networks (MLP) were used in this study. Figure 1 shows the conceptual model of the research.

\section{RESULTS}

Initially, a summary of the descriptive statistics of the variables used in the study is presented. The results of the neural network model estimation are reported then. Finally, the prediction accuracy of the model used is examined and their prediction for 2020 is presented.

The model of this research considers Olympic medals as a commercial product that is produced under the Cobb-Douglas production function process as a result of the combination of the two institutions of the population (as labor force) and GDP per capita (as capital). In this study, political stability is added to the model as a critical institution.

Table 2 shows the values of these three variables for 2004, 2008, 2012, 2016 and 2020. Population in a million and GDP per dollar are measured at the 2010 constant price. From a set of global governance indicators, the index of political stability is extracted. The index adopts a value of between -2.5 and 2.5 , in the way that 2.5 means complete political instability and 2.5 means absolute stability.

Values for 2020, the target year of this study, are estimated based on the mean growth rate of 2000 to 2017. About the index of political stability, the index value for 2016 has been used because of the timeliness of significant developments in a country's political structure.

Table 2 Reports the Number of Medals Taken by each of the Countries Studied and their Rank in 2004, 2008, 2012 and 2016. Since the Colors of the Medals do not Make a Significant Difference to the Prediction Results, all the Medals are Included in the Estimates Together.

Input stage
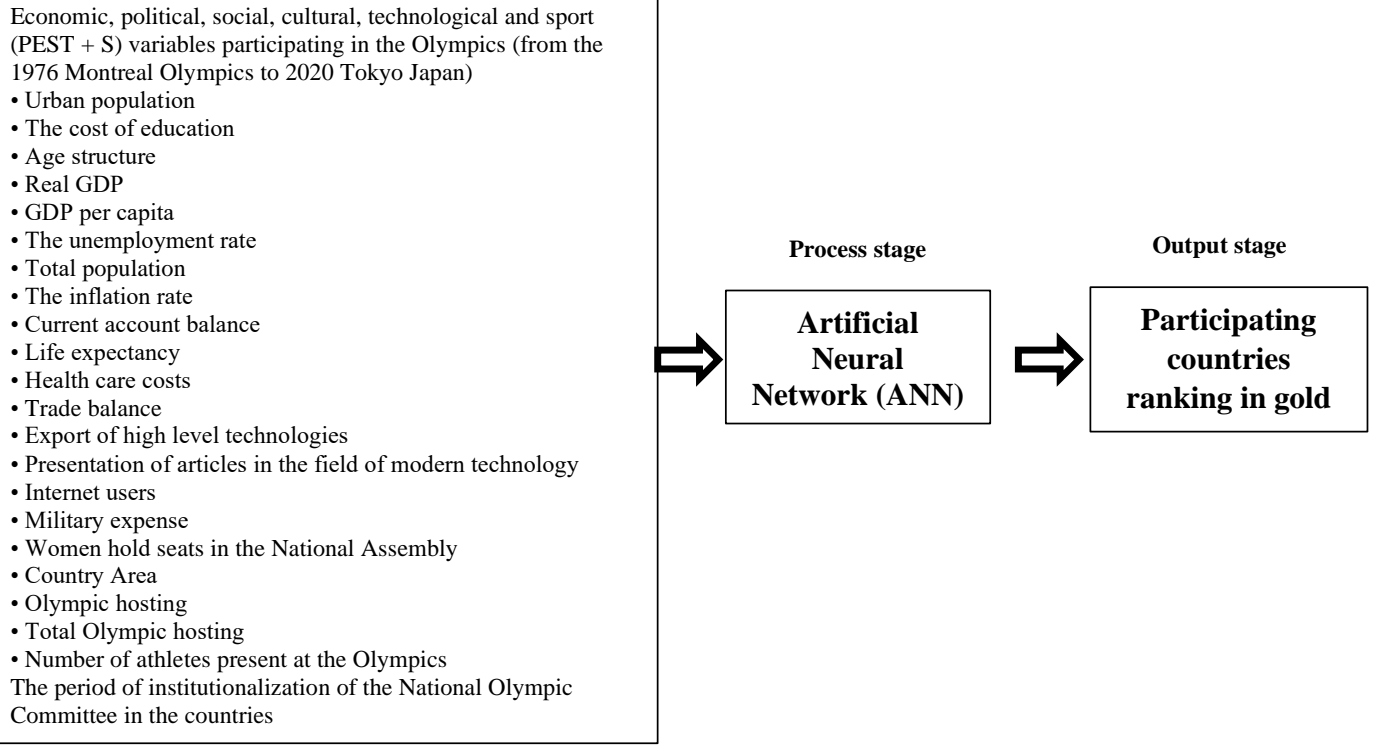

Figure 1. The conceptual pattern of research 
Table 2. Reports the Number of Medals Taken by each of the Countries Studied and their Rank in 2004, 2008, 2012 and 2016. Since the Colors of the Medals do not Make a Significant Difference to the Prediction Results, all the Medals are Included in the Estimates Together

\begin{tabular}{|cccc|}
\hline Year & Population, Million & $\begin{array}{c}\text { GDP Per Capita, Dollars Per Person } \\
\text { Iran }\end{array}$ & Political Stability \\
2004 & 70 & 5573 & -0.76 \\
2008 & 73 & 6257 & -0.94 \\
2012 & 76 & 6053 & -1.32 \\
2016 & 80 & 6734 & -0.81 \\
2020 & 84 & 7442 & -0.81 \\
2020 & 9 & 50527 & 0.91 \\
& & Argentina & -0.61 \\
2004 & 39 & 7914 & -0.09 \\
2008 & 40 & 10125 & 0.10 \\
2012 & 42 & 10558 & 0.20 \\
2016 & 44 & 10206 & 0.20 \\
2020 & 46 & 10905 & -0.23 \\
2004 & 293 & 47614 & 0.59 \\
2008 & 304 & 49365 & 0.63 \\
2012 & 314 & 49498 & 0.40 \\
2016 & 323 & 52319 & 0.40 \\
2020 & 334 & 54714 & \\
\hline
\end{tabular}

Table 3. Number of Medals Awarded at the Olympics and Ranking of Participating Countries

\begin{tabular}{|lcccccccc|}
\hline & \multicolumn{2}{c}{$\mathbf{2 0 0 4}$} & \multicolumn{2}{c}{$\mathbf{2 0 0 8}$} & \multicolumn{2}{c}{$\mathbf{2 0 1 2}$} & \multicolumn{2}{c|}{$\mathbf{2 0 1 6}$} \\
Iran & Medal & Rating & Medal & Rating & Medal & Rating & Medal & Rating \\
United States & 6 & 16 & 2 & 19 & 13 & 11 & 8 & 13 \\
Argentina & 101 & 1 & 110 & 1 & 103 & 1 & 121 & 1 \\
\hline
\end{tabular}

Analysis. Finally, based on the neural network method, a neural network model was used to predict the number of Olympic medals received by each country.

Network Structure. The overall structure of the estimated model is shown in Table 4. In the designed model, $70.24 \%$ of the observations (144 observations) were selected as the training group and $29.76 \%$ of the comments (61 comments) as the experimental group. All the comments have sufficient credit features according to preliminary estimates. Hence, none of the comments were excluded.

Table 4. Pattern Structure

\begin{tabular}{|lcc|}
\hline & Number & Percentage \\
Sample & & \\
$\quad$ Practice & 144 & 70.24 \\
$\quad$ Test & 61 & 29.76 \\
Valid & 205 & 1 \\
Removed & 0 & \\
Total & 205 & \\
\hline
\end{tabular}

The network structure designed for this research is shown in Table 5. The input layer of the model consists of two factors (year and country) and the three explanatory variables (GDP per capita, population, political stability). The standard method was the scale change method in this layer. Worth noting that in this section, various combinations of explanatory variables and factors including other economic and political characteristics of the countries under study (such as the structure of foreign trade and the existence or absence of a dictatorship) were used and the present model reported the least prediction error.

The network designed for this study consists of two hidden layers. The first layer contains 41 sections and the second layer includes five parts. The activation function for this layer is the function of the hyperbolic tangent.

\begin{tabular}{|c|c|}
\hline \multicolumn{2}{|l|}{ Input layer } \\
\hline \multicolumn{2}{|l|}{ Factors } \\
\hline 1 & Year \\
\hline 2 & Country \\
\hline \multicolumn{2}{|l|}{ The explanatory variables } \\
\hline 1 & GDP per capita \\
\hline 2 & population \\
\hline 3 & Political stability \\
\hline $\begin{array}{l}\text { Number of units (except unit of } \\
\text { thrust) }\end{array}$ & 49 \\
\hline Scale shift method & Standard \\
\hline \multicolumn{2}{|c|}{ The hidden layer } \\
\hline The number of layers hidden & 2 \\
\hline Number of units in the first layer & 41 \\
\hline Number of units in the second layer & 5 \\
\hline Activation function & Hyperbolic Tangent \\
\hline \multicolumn{2}{|l|}{ Output layer } \\
\hline The dependent variables & $\begin{array}{l}\text { Olympic medal } \\
\text { count }\end{array}$ \\
\hline $\begin{array}{l}\text { Number of units (except unit of } \\
\text { thrust) }\end{array}$ & 1 \\
\hline Scale shift method & Standard \\
\hline Activation function & Unique \\
\hline Error function & sum of squares \\
\hline
\end{tabular}

Only one unit (number of Olympic medals) is included in the output layer. The scale change 
method in this layer is the standard method. The activation function is of the unique type and the error function is the type of the sum of squares.

Table 6. Estimated Model Summary

\begin{tabular}{|lc|}
\hline $\begin{array}{l}\text { Practice } \\
\text { Total error } \\
\text { squares }\end{array}$ & 4.12 \\
$\begin{array}{l}\text { Relative error } \\
\text { Stop Law }\end{array}$ & $\begin{array}{c}\text { One successive step without error } \\
\text { reduction, based on test sample }\end{array}$ \\
$\begin{array}{l}\text { Practice time } \\
\text { Test }\end{array}$ & $00: 00.25$ \\
$\begin{array}{l}\text { Total error } \\
\text { squares } \\
\text { Relative error }\end{array}$ & 7.09 \\
\hline
\end{tabular}

The values predicted by the model are compared with the actual costs of the dependent variable in Figure 2. These points are just a few degrees off the 45-degree line, as can be seen in the diagram. This indicates a relatively high accuracy in the prediction.

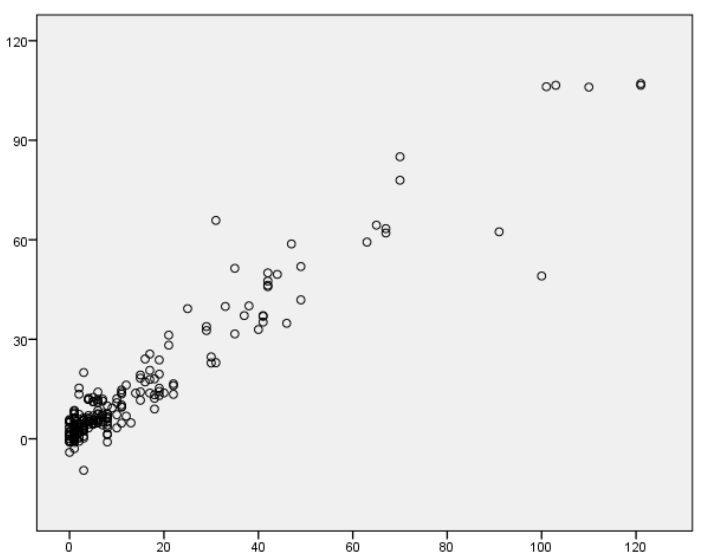

Figure 2. The Predicted Values Versus the Estimated Values

The Results of the Estimation. A summary of the estimated critical values of the model is presented in Table 6. In the sports group, based on the estimation results, the sum of squares of error after reaching balance was 4.12 units. The relative error in this group was also $5.77 \%$. On the other hand, in the experimental group, the sum of squares of error was 7.09 units and the relative failure of estimation in this group was reported $14.28 \%$.

The importance of each of the explanatory variables and factors in predicting the dependent variable is shown in Table 7. In other words, these values represent the percentage of the sensitivity of the dependent variable to each of the explanatory variables. According to the estimation results, the population with $32.44 \%$ was the most important predictor. After that, there are GDP per capita at $23.33 \%$ and finally political stability at $11.82 \%$. Among the factors, the country with $29.93 \%$ is of greater importance relative to year with $2.48 \%$. This is consistent with the results of the two previous models.

Table 7. The Importance of Explanatory Variables

\begin{tabular}{|lcc|}
\hline Variable & $\begin{array}{c}\text { Importance, } \\
\text { \% }\end{array}$ & $\begin{array}{c}\text { Normalized } \\
\text { significance, \% }\end{array}$ \\
Year & 2.48 & 7.64 \\
Country & 29.93 & 92.26 \\
GDP per capita & 23.33 & 71.93 \\
Population & 32.44 & 100 \\
Political & 11.82 & 36.42 \\
stability & & \\
\hline
\end{tabular}

\section{Olympic Prediction}

Model Accuracy Check-in 2004. The ranking of each of the countries at the 2004 Olympics is shown in Figure 3, along with the values predicted by the model which are used in this study. The model had relatively good accuracy in predicting the ranking of the countries under review based on the graph.

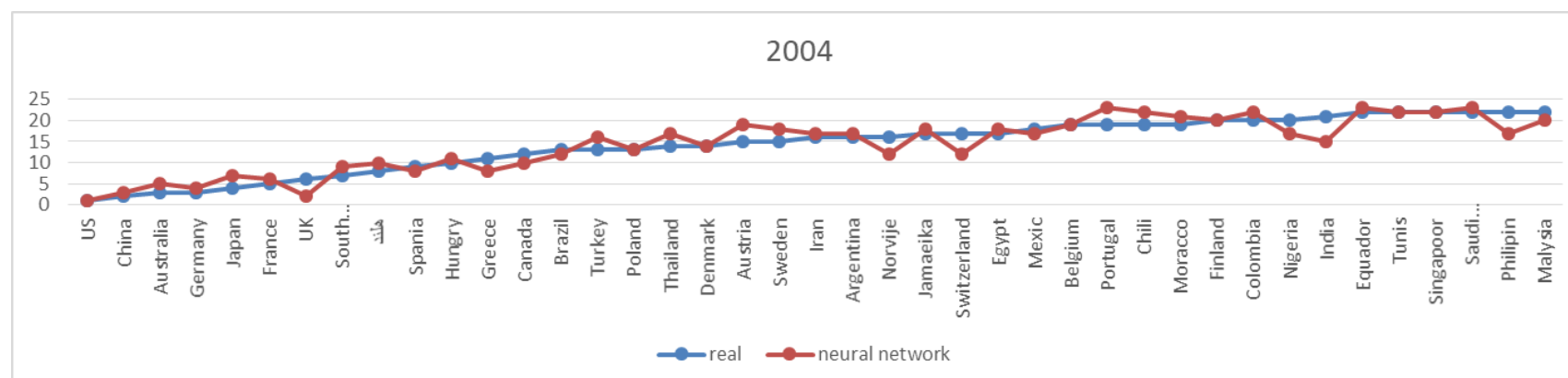

Figure 3. Actual and Predicted Ranking of the 2004 Olympic Games 
Table 8. Rank and Number of Medals Received in 2008 (Real vs. Predicted)

\begin{tabular}{|lcccc|}
\hline & \multicolumn{3}{c}{ Neural Network } & \multicolumn{2}{c|}{ Real } \\
Rating & Medal Count & Rating & Medal Count \\
United States & 1 & 106 & 1 & 110 \\
China & 3 & 49 & 2 & 100 \\
the UK & 2 & 59 & 3 & 47 \\
\hline Australia & 6 & 35 & 4 & 46 \\
Germany & 5 & 37 & 5 & 41 \\
France & 7 & 33 & 6 & 40 \\
South Korea & 8 & 23 & 7 & 31 \\
\hline Japan & 4 & 39 & 8 & 25 \\
Spain & 12 & 13 & 9 & 18 \\
Netherlands & 10 & 17 & 10 & 16 \\
Canada & 11 & 14 & 11 & 14 \\
Jamaica & 19 & 3 & 12 & 10 \\
Poland & 19 & 3 & 13 & 8 \\
Brazil & 15 & 7 & 14 & 7 \\
Denmark & 14 & 8 & 14 & 7 \\
Turkey & 17 & 5 & 15 & 6 \\
Norway & 13 & 11 & 15 & 6 \\
Swiss & 13 & 11 & 16 & 5 \\
Hungary & 13 & 11 & 16 & 5 \\
Sweden & 16 & 6 & 17 & 4 \\
Austria & 19 & 3 & 18 & 3 \\
\hline Argentina & 18 & 4 & 18 & 3 \\
Finland & 19 & 3 & 18 & 3 \\
Greece & 9 & 20 & 18 & 3 \\
Iran & 20 & 2 & 19 & 2 \\
Belgium & 17 & 5 & 19 & 2 \\
Thailand & 18 & 4 & 19 & 2 \\
Columbia & 22 & 0 & 19 & 2 \\
Mexico & 17 & 5 & 19 & 2 \\
India & 15 & 7 & 19 & 2 \\
Ecuador & 20 & 2 & 20 & 1 \\
Portugal & 22 & 0 & 20 & 1 \\
Tunisia & 22 & 0 & 20 & 1 \\
Singapore & 22 & 0 & 20 & 1 \\
Chile & 22 & 0 & 20 & 1 \\
Malaysia & 20 & 2 & 20 & 1 \\
Morocco & 20 & 2 & 20 & 1 \\
Egypt & 18 & 4 & 20 & 1 \\
Saudi Arabia & 21 & 1 & 21 & 0 \\
Philippines & 17 & 5 & 21 & 0 \\
Nigeria & 17 & 5 & 21 & 0 \\
\hline & & & & \\
\hline
\end{tabular}

Table 9. Rank and Number of Medals Received in 2012 (Real

\begin{tabular}{|c|c|c|c|c|}
\hline \multicolumn{5}{|c|}{$\begin{aligned} \text { vs. Predicted) } \\
\end{aligned}$} \\
\hline & \multicolumn{2}{|c|}{ Neural Network } & \multicolumn{2}{|r|}{ Real } \\
\hline & Rating & Medal count & Rating & Medal count \\
\hline United States & 1 & 107 & 1 & 103 \\
\hline China & 3 & 62 & 2 & 91 \\
\hline the UK & 2 & 64 & 3 & 65 \\
\hline Germany & 5 & 50 & 4 & 44 \\
\hline Japan & 6 & 40 & 5 & 38 \\
\hline Australia & 4 & 51 & 6 & 35 \\
\hline France & 7 & 32 & 6 & 35 \\
\hline South Korea & 8 & 25 & 7 & 30 \\
\hline Netherlands & 10 & 14 & 8 & 20 \\
\hline Spain & 9 & 18 & 9 & 18 \\
\hline Canada & 11 & 12 & 9 & 18 \\
\hline Hungary & 12 & 9 & 9 & 18 \\
\hline Brazil & 9 & 18 & 10 & 17 \\
\hline Iran & 15 & 5 & 11 & 13 \\
\hline Jamaica & 13 & 7 & 12 & 12 \\
\hline Poland & 15 & 5 & 13 & 11 \\
\hline Denmark & 12 & 9 & 14 & 9 \\
\hline Sweden & 15 & 5 & 15 & 8 \\
\hline Columbia & 19 & 1 & 15 & 8 \\
\hline Mexico & 14 & 6 & 15 & 8 \\
\hline India & 12 & 9 & 16 & 6 \\
\hline Argentina & 13 & 7 & 17 & 4 \\
\hline Thailand & 15 & 5 & 17 & 4 \\
\hline Swiss & 11 & 12 & 17 & 4 \\
\hline Egypt & 15 & 5 & 17 & 4 \\
\hline Norway & 11 & 12 & 17 & 4 \\
\hline Belgium & 18 & 2 & 18 & 3 \\
\hline Turkey & 14 & 6 & 18 & 3 \\
\hline Tunisia & 14 & 6 & 18 & 3 \\
\hline Finland & 17 & 3 & 18 & 3 \\
\hline Singapore & 20 & 0 & 19 & 2 \\
\hline Malaysia & 18 & 2 & 19 & 2 \\
\hline Greece & 16 & 4 & 19 & 2 \\
\hline Portugal & 19 & 1 & 20 & 1 \\
\hline Saudi Arabia & 20 & 0 & 20 & 1 \\
\hline Morocco & 16 & 4 & 20 & 1 \\
\hline Austria & 18 & 2 & 21 & 0 \\
\hline Ecuador & 18 & 2 & 21 & 0 \\
\hline Chile & 20 & 0 & 21 & 0 \\
\hline Philippines & 15 & 5 & 21 & 0 \\
\hline Nigeria & 14 & 6 & 21 & 0 \\
\hline
\end{tabular}

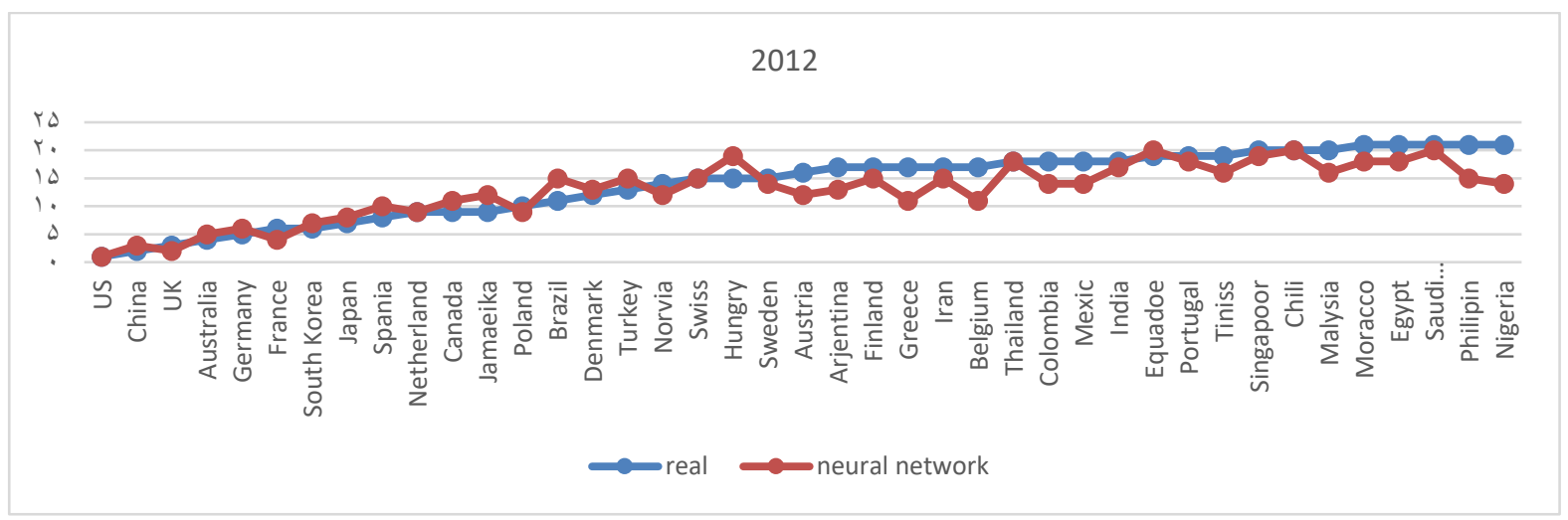

Figure 4. Actual and predicted 2012 Olympic rankings

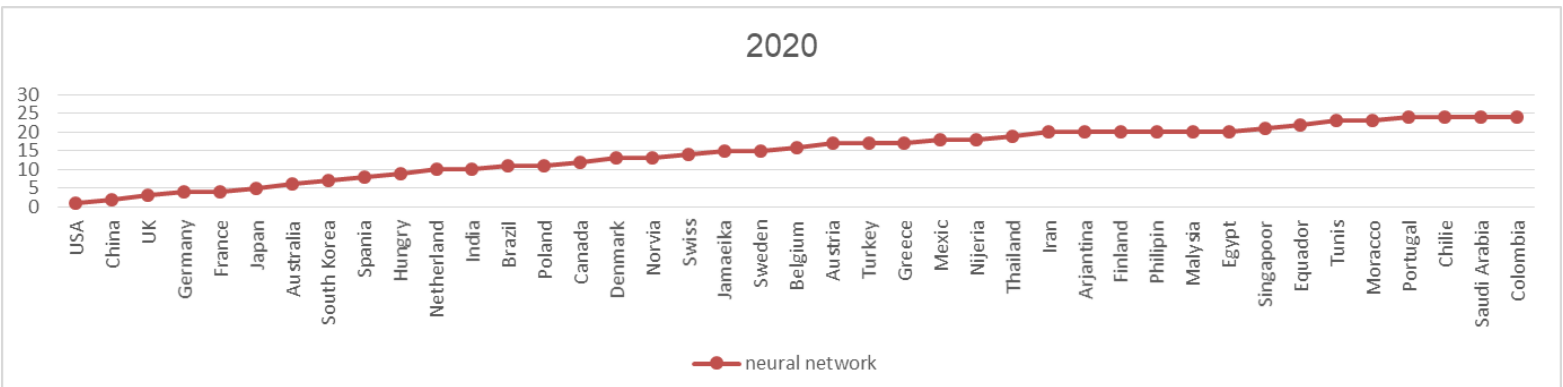

Figure 5. Prediction of the Ranking of 2020 Olympics 
Table 10. Rank and Number of Medals Received in 2016 (Real vs. Predicted)

\begin{tabular}{|c|c|c|c|c|}
\hline & \multicolumn{2}{|c|}{ Neural Network } & \multicolumn{2}{|r|}{ Real } \\
\hline & Rating & Medal Count & Rating & Medal Count \\
\hline United States & 1 & 107 & 1 & 121 \\
\hline China & 2 & 78 & 2 & 70 \\
\hline the UK & 3 & 63 & 3 & 67 \\
\hline Germany & 5 & 48 & 4 & 42 \\
\hline France & 4 & 50 & 4 & 42 \\
\hline Japan & 6 & 37 & 5 & 41 \\
\hline Australia & 7 & 33 & 6 & 29 \\
\hline Canada & 12 & 17 & 7 & 22 \\
\hline South Korea & 8 & 31 & 8 & 21 \\
\hline Brazil & 15 & 13 & 9 & 19 \\
\hline Netherlands & 10 & 20 & 9 & 19 \\
\hline Spain & 9 & 21 & 10 & 17 \\
\hline Denmark & 14 & 14 & 11 & 15 \\
\hline Hungary & 11 & 18 & 11 & 15 \\
\hline Jamaica & 18 & 10 & 12 & 11 \\
\hline Sweden & 15 & 13 & 12 & 11 \\
\hline Poland & 13 & 15 & 12 & 11 \\
\hline Iran & 20 & 7 & 13 & 8 \\
\hline Turkey & 19 & 8 & 13 & 8 \\
\hline Columbia & 24 & 1 & 13 & 8 \\
\hline Swiss & 16 & 12 & 14 & 7 \\
\hline Belgium & 14 & 14 & 15 & 6 \\
\hline Thailand & 21 & 6 & 15 & 6 \\
\hline Greece & 17 & 11 & 15 & 6 \\
\hline Malaysia & 22 & 5 & 16 & 5 \\
\hline Mexico & 20 & 7 & 16 & 5 \\
\hline Argentina & 23 & 3 & 17 & 4 \\
\hline Norway & 16 & 12 & 17 & 4 \\
\hline Tunisia & 21 & 6 & 18 & 3 \\
\hline Egypt & 21 & 6 & 18 & 3 \\
\hline India & 15 & 13 & 19 & 2 \\
\hline Austria & 19 & 8 & 20 & 1 \\
\hline Portugal & 25 & 0 & 20 & 1 \\
\hline Singapore & 23 & 3 & 20 & 1 \\
\hline Finland & 21 & 6 & 20 & 1 \\
\hline Philippines & 21 & 6 & 20 & 1 \\
\hline Morocco & 23 & 3 & 20 & 1 \\
\hline Nigeria & 19 & 8 & 20 & 1 \\
\hline Ecuador & 23 & 3 & 21 & 0 \\
\hline Chile & 25 & 0 & 21 & 0 \\
\hline Saudi Arabia & 24 & 1 & 21 & 0 \\
\hline
\end{tabular}

Model Accuracy Check-in 2008. The number of medals obtained and the ranking of each of the countries at the 2008 Olympics, along with the values predicted by the model used in this study are shown in Table 8. As can be seen from the results, the neural network method was more accurate in predicting the number of medals obtained for the countries which have many medals.

Model Accuracy Check-in 2012. The ranking and the number of medals obtained at the 2012 Olympics by the countries studied, along with the values predicted by the neural network model is reported in Table 9. As can be seen, the accuracy of the neural network model is higher in predicting the number of medals obtained for countries which have many medals. Figure 4 shows the ranking of each of the countries in the 2012 Olympics in terms of the model prediction.

Model Accuracy Check-in 2016. The ranking and the number of medals obtained at the 2016 Olympics by the countries studied, along with the model prediction used in this study is reported in Table 10. As can be seen, the neural network model is of high accuracy in predicting the number of medals taken.

Table 11. Forecast of the Rank and Number of Olympic

\begin{tabular}{|lcc|}
\multicolumn{3}{c}{ Medals in 2020 } \\
\hline \multicolumn{3}{|c|}{ Neural Network } \\
\hline United States & Medal Count & Rating \\
China & 107 & 1 \\
the UK & 85 & 2 \\
Germany & 62 & 3 \\
France & 46 & 4 \\
Japan & 46 & 4 \\
Australia & 35 & 5 \\
South Korea & 34 & 6 \\
Spain & 28 & 7 \\
Hungary & 26 & 8 \\
Netherlands & 19 & 9 \\
India & 15 & 10 \\
Brazil & 15 & 10 \\
Poland & 14 & 11 \\
Canada & 14 & 11 \\
Denmark & 13 & 12 \\
Norway & 12 & 13 \\
Swiss & 12 & 13 \\
Jamaica & 11 & 14 \\
Sweden & 10 & 15 \\
Belgium & 10 & 15 \\
Austria & 8 & 16 \\
Turkey & 7 & 17 \\
Greece & 7 & 17 \\
Mexico & 7 & 17 \\
Nigeria & 6 & 18 \\
Thailand & 6 & 18 \\
Iran & 5 & 19 \\
Argentina & 4 & 20 \\
Finland & 4 & 20 \\
Philippines & 4 & 20 \\
Malaysia & 4 & 20 \\
Egypt & 4 & 20 \\
Singapore & 4 & 20 \\
Ecuador & 3 & 21 \\
Tunisia & 2 & 22 \\
Morocco & 1 & 23 \\
Portugal & 1 & 23 \\
Chile & 0 & 24 \\
Saudi Arabia & 0 & 24 \\
Columbia & 0 & 24 \\
& 0 & 24 \\
\hline
\end{tabular}

Prediction of 2020. The ranking and the number of medals obtained at the 2020 Olympics by the countries studied are reported in Table 11. According to the results said, the United States will rank first in 2020, China will rank second and one of the two countries of England or Japan will rank third.

Figure 5 reports the predicted ranking of the countries under study at the 2020 Olympics based on the model used in this study.

\section{DISCUSSION}

Scientific methods are the basis for change and progress in all fields in developed countries. This research is designed in line with future Olympic planning (2020 Tokyo) using a neural network model based on the neural network method to predict the number of Olympic medals obtained by each of the countries. Initial estimates of all the observations have sufficient credit features and as a result, no consideration is excluded. Given the 
accuracy of this method compared to the prediction of past Olympics and comparing it with the actual results, the value and validity of this research for the 2020 Olympics can be found. Also, given the fact that the model input layer consists of two factors (year and country) and three explanatory variables (GDP per capita, population, political stability), the comprehensiveness of this research in most of the areas useful in the prediction can be acknowledged and this can help consider the interpretation of the study more confident about the results. The network designed for this study consists of 2 hidden layers (the first layer consists of 41 sections and the second layer consists of five parts). Where the activation function for this layer is the function of the hyperbolic tangent.

Additionally, only one unit (number of Olympic medals) is included in the output layer. The parameters affecting the predicting model are population, country, GDP per capita, political stability, and the year under study. Only one unit (number of Olympic medals) is included in the output layer. The comparison method in this layer is the standard method. The activation function is of the unique type and the error function is for the kind of sum of squares.

In 2004, Iran won 6 Olympic medals at the Olympics. It won only 2 medals at the 2008 Olympics. In 2012, Iran won 13 medals at the Olympics. Iran won eight medals at the 2016 Olympics. Except for 2012, the closest prediction of the medals obtained by Iran at the Olympics is seen in the neural network model. This year, too, the neural network model prediction has the least distance to the real value. According to the neural network model, in 2020, Iran will win four medals in the Olympics. This value will be five medals based on the Tobit model and six medals based on the Panel model.

\section{CONCLUSION}

The dependent variable in the model used was the number of Olympic medals obtained at the 2004, 2008, 2012 and 2016 Olympics. The explanatory variables used were GDP per capita, population and political stability of the countries under study. The model has a relatively functional specification and the coefficient of estimation is significant at the level of $90 \%$ or more based on the results of the study. The predicted value is also centered on the axis of 45 degrees line (the explanatory value is 85.19). Finally, the prediction for the year 2020 was reported. According to estimates, the United States, China and England or Japan will rank in the top three of the 2020 Olympics, respectively. According to the neural network model, in 2020, Iran will win four medals in the Olympics.

\section{APPLICABLE REMARKS}

- The results of this research can be useful for the planning of the audiences of the study such as the Ministry of Sports, the National Olympic Committee, federations, boards, education and even professional clubs and even sponsors of sports communities.

- Considering that the population participating in the Olympic Games is of a specific age group, planning can focus on the age group and can be considered in future estimates.

- Given that this research uses a theoretical model (PEST+S) and a neural network model, sport policy makers in countries can use the identified indicators and components in their future planning using this research with a scientific approach to have a more fruitful participation in the Olympic Games.

- Other practical results of the research can be to modify expectations and avoid frustration with sports fans concerning the existing potentials.

\section{REFERENCES}

1. JS A. Principles of Forecasting: Springer; 2001.

2. DeLurgio SA. Forecasting principles and applications: Irwin Professional Publishing; 1998.

3. Lucas JW, Lovaglia MJ. Self-handicapping: Gender, race, and status. Curr Res Soc Psychol. 2005;10(15):234-249.

4. del Corral J, Prieto-Rodríguez J. Are differences in ranks good predictors for Grand Slam tennis matches? Int J Forecast. 2010;26(3):551-563. doi: 10.1016/j.ijforecast.2009.12.006

5. Song C, Boulier BL, Stekler HO. The comparative accuracy of judgmental and model forecasts of American football games. Int J Forecast. 2007;23(3):405-413. doi: 10.1016/j.ijforecast.2007.05.003

6. Armstrong JS. Methods to Elicit Forecasts from Groups: Delphi and Prediction Markets Compared. SSRN Electron J. 2008. doi: 10.2139/ssrn.1153124 
7. Green BC. Building Sport Programs to Optimize Athlete Recruitment, Retention, and Transition: Toward a Normative Theory of Sport Development. J Sport Manage. 2005;19(3):233-253. doi: 10.1123/jsm.19.3.233

8. De Bosscher V, De Knop P, van Bottenburg M, Shibli S, Bingham J. Explaining international sporting success: An international comparison of elite sport systems and policies in six countries. Sport Manage Rev. 2009;12(3):113-136. doi: 10.1016/j.smr.2009.01.001

9. Klaassen FJGM, Magnus JR. Forecasting the winner of a tennis match. European J Oper Res. 2003;148(2):257-267. doi: 10.1016/s0377-2217(02)00682-3

10. Smith T, Schwertman NC. Can the NCAA Basketball Tournament Seeding be Used to Predict Margin of Victory? American Statistic. 1999;53(2). doi: 10.2307/2685724

11.Goldstein DG, Gigerenzer G. Fast and frugal forecasting. Int J Forecast. 2009;25(4):760-772. doi: 10.1016/j.ijforecast.2009.05.010

12. Grove SJ, Fisk RP, John J. The future of services marketing: forecasts from ten services experts. J Serv Mark. 2003;17(2):107-121. doi: 10.1108/08876040310467899

13. Wright G, Lawrence MJ, Collopy F. The role and validity of judgment in forecasting. Int J Forecast. 1996;12(1):1-8. doi: 10.1016/0169-2070(96)00674-7

14. Abrahart R, Kneale PE, See LM. Neural Networks for Hydrological Modeling. London: CRC Press; 2004.

15. Forrest D, Sanz I, Tena JD. Forecasting national team medal totals at the Summer Olympic Games. Int J Forecast. 2010;26(3):576-588. doi: 10.1016/j.ijforecast.2009.12.007

16. Derevenco P, Albu M, Duma E. Forecasting of top athletic performance. Rom j physiol physiol sci. 2002;39:57-62.

17. Seager R, Goddard L, Nakamura J, Henderson N, Lee DE. Dynamical Causes of the 2010/11 TexasNorthern Mexico Drought. J Hydrometeorol. 2014;15(1):39-68. doi: 10.1175/jhm-d-13-024.1

18. De Bosscher V, De Knop P, Van Bottenburg M, Shibli S. A Conceptual Framework for Analysing Sports Policy Factors Leading to International Sporting Success. Eur Sport Manage Q. 2006;6(2):185-215. doi: 10.1080/16184740600955087

19.Ning W, Kuan-jiang B, Zhi-fa Y. Analysis and forecast of Shaanxi GDP based on the ARIMA Model. Asian Agric Res. 2010;2(1812-2016-143365):34-41.

20.Iyer SR, Sharda R. Prediction of athletes performance using neural networks: An application in cricket team selection. Expert Syst Appl. 2009;36(3):5510-5522. doi: 10.1016/j.eswa.2008.06.088

21. Grant A, Johnstone D. Finding profitable forecast combinations using probability scoring rules. Int $J$ Forecast. 2010;26(3):498-510. doi: 10.1016/j.ijforecast.2010.01.002

22. Sotiriadou K, Shilbury D. Australian Elite Athlete Development: An Organisational Perspective. Sport Manage Rev. 2009;12(3):137-148. doi: 10.1016/j.smr.2009.01.002

23. Condon EM, Golden BL, Wasil EA. Predicting the success of nations at the Summer Olympics using neural networks. Comput Oper Res. 1999;26(13):1243-1265. doi: 10.1016/s0305-0548(99)00003-9

24. Bernard AB, Busse MR. Who Wins the Olympic Games: Economic Resources and Medal Totals. Rev Econ Stat. 2004;86(1):413-417. doi: 10.1162/003465304774201824

25. Rivenburgh N. The Olympic Games, media and the challenges of global image making: university lecture on the Olympics [on line article], Barcelona: Centre d'Estudios Olímpics (UAB). International Chair in Olympism (IOC-UAB)2004.

26. Damisch L, Mussweiler T, Plessner H. Olympic medals as fruits of comparison? Assimilation and contrast in sequential performance judgments. J Exp Psychol Appl. 2006;12(3):166-178. doi: 10.1037/1076-898X.12.3.166 pmid: 16953743

27. Churilov L, Flitman A. Towards fair ranking of Olympics achievements: the case of Sydney 2000. Comput Oper Res. 2006;33(7):2057-2082. doi: 10.1016/j.cor.2004.09.027

28. Kuper GH, Sterken E. Participation and performance at the London 2012 Olympics. SOM Res Rep. 2012;12006.

29. Strauss A, Corbin JM. Grounded theory in practice: Sage; 1997. 